\title{
Modes of operation and design features of pulse cables for the ITER project
}

\author{
Mikhail Doronin ${ }^{1, *}$, George Greshnyakov ${ }^{1}$, Nikolay Korovkin ${ }^{1}$ \\ ${ }^{1}$ Peter the Great Saint-Petersburg Polytechnic University, Saint-Petersburg, Russian Federation
}

\begin{abstract}
Cables with high current capacity are used in power devices, including special-purpose ones operating in impulse modes. It is important to ensure low inductance of such cables, because these type cable products are often used as connecting products. This article discusses the problems that arise in the design and manufacture of special low-inductance impulse cables (SLIC) for power supply and protection of the superconducting magnetic system of the ITER reactor (France), the distinguishing features of which are the optimum ratio of insulation thickness and throughput at low inductance.
\end{abstract}

\section{Introduction}

At the initiative of the USSR in 1985, a number of states joined together to implement the Tokamak project - to create conditions for controlled thermonuclear fusion. In 1992, Russia, the European Union, Japan and the United States signed a quadrilateral agreement on the development of ITER (International Thermonuclear Experimental Reactor). The city of Cadarache (France) was chosen as the site for the construction of the reactor. Russia has undertaken part of the obligations to create a thermonuclear reactor.

Before the beginning of each operating cycle, the energy in the poloidal magnetic system ITER will be up to 8 GJ [1]. In part, this energy will be used up to initiate breakdown of the gas mixture and the onset of the rise of the plasma current on the torus bypass [2]. These processes are implemented on special hybrid (mechanical and semiconductor) high-current switches and powerful energy-absorbing resistors, which dissipate the energy of the coils of the poloidal system when switches operate.

The article considers:

- problems related to the development of cable designs for connecting energy-absorbing resistors to operational and protective current switching devices in the power output system from superconducting reactor windings; $\mathrm{kV}$;

- Experience of development of SLIC for pulse modes with bipolar voltage pulses up to 12

- Simulation of electromagnetic and temperature fields was performed to study the ability to preserve the insulating properties of cables and evaluated the temperature regime of insulation under periodic pulses.

\footnotetext{
*Corresponding author: mvdoronin93@gmail.com
} 
In modern power engineering, there are not many technical systems capable of carrying out significant currents (dozens of kA). One of them are busbars, used to transmit significant amounts of electricity for short distances [3] (for example, from a generator to a step-up transformer). Busbars have found application in medium-power thermal power plants, large block power stations, nuclear power stations and hydroelectric power stations [4]. However, due to the specificity of the pulse operating modes, the busbars are not suitable for the ITER system.

\section{SLIC construction and operation modes}

\subsection{Modes of SLIK operation}

Main technical characteristics of cable systems (CS): operating voltage - impulse, bipolar with positive amplitude $\approx 8.5 \mathrm{kV}$, inductance - no more than $0.2 \mu \mathrm{G} / \mathrm{m}$, exponentially changing operating current with time constant - up to $20 \mathrm{~s}$. The amplitude of the current in various modes is 1.2-12 kA (Fig.1). The mode of rare pulses (the current is shown in Fig. 1-a) is characterized by an amplitude value of about $11.5 \mathrm{kA}$ with a front length of $10 \mathrm{~ms}$. The interval between pulses is at least 10 hours. The mode of periodic pulses (curves 1-b, 1-c) assumes a pause between pulses for at least 20 minutes, while the current amplitude for one type of cable is about $5 \mathrm{kA}$, for the other - about $1.5 \mathrm{kA}$.

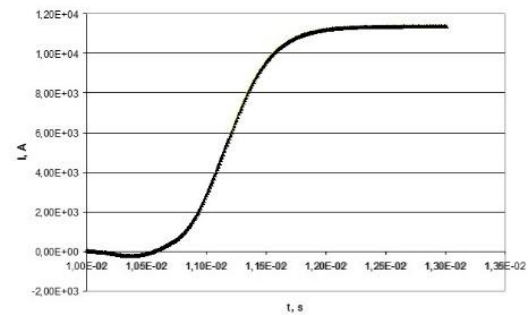

a)

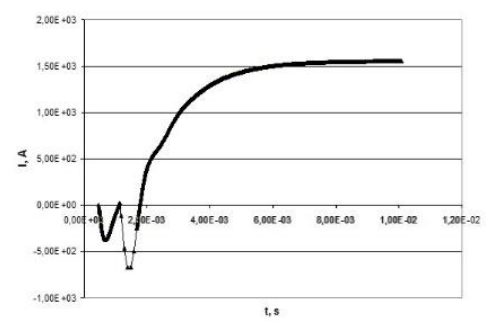

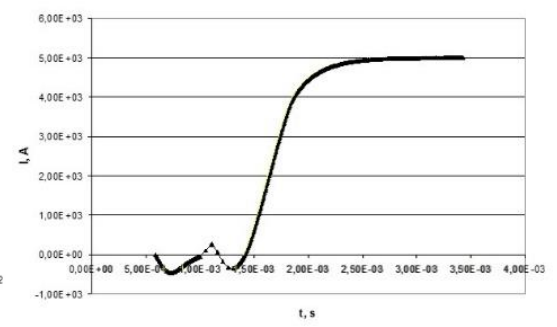

b)

c)

Fig. 1. Dependence of the SLIC current on time.

The low value of the inductance of the SLIC is achieved by using a coaxial design, in addition, for safety reasons, a protective screen is used which can be grounded. 


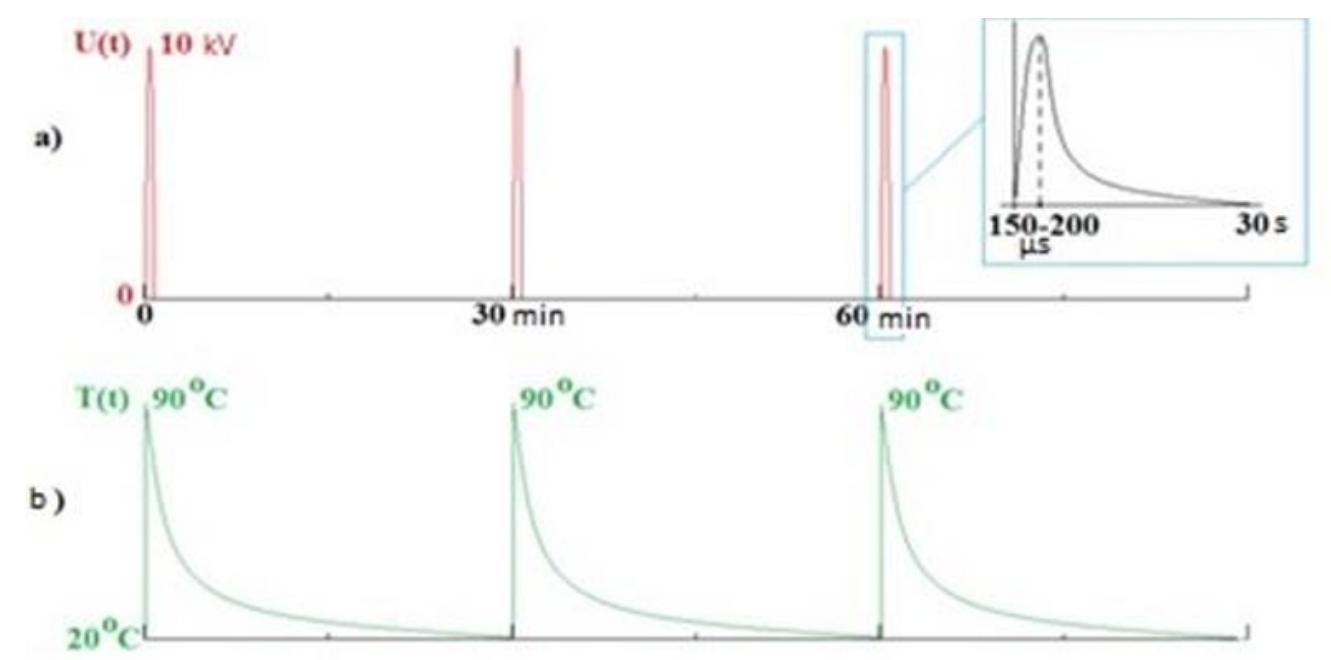

Fig. 2 a) Shape of the acting voltage on cable insulation;

b) Changing the temperature of the cable's inner conductor in time.

A feature of the developed cables is that they are operated at a voltage having a significant constant component (Fig. 2). It is necessary to take into account the possibility of accumulating a space charge in the thickness and at the interfaces of insulation, which leads to local distortion and an increase in the magnitude of the electric field. It is known, that these processes lead to premature failure of XLPE cables.

\subsection{SLIC construction}

The cables proposed and considered in the article have the following design options:

- cables with a cross-section of conductors 120 and $25 \mathrm{~mm}^{2}$, intended for the switching center;

- cable with a cross-section of conductors $300(400) \mathrm{mm}^{2}$ - for rapid energy removal (rapid discharge of the capacitive storage).

To minimize the values of the inductance between the external and inner conductors, and to minimize the increase of the external and internal electromagnetic fields, the SLIC have a triaxle construction $[5,6,7]$. Design sketches for cables with cross-sections of conductors 120 $\mathrm{mm}^{2}$ and $400 \mathrm{~mm}^{2}$ are shown in Fig. 3 and in Table 1.

The core was stranded, round in shape, compacted, and made of copper wires of MM mark. Insulation of the core (inner insulation) and external conductor (external insulation) for cables of all cross-sections is carried out with a composition of LE 4421M (95\%) silane cross-linked polyethylene and LE 4431 catalyst (5\%) manufactured by "Borealis" 
Fig.3. SLIC construction

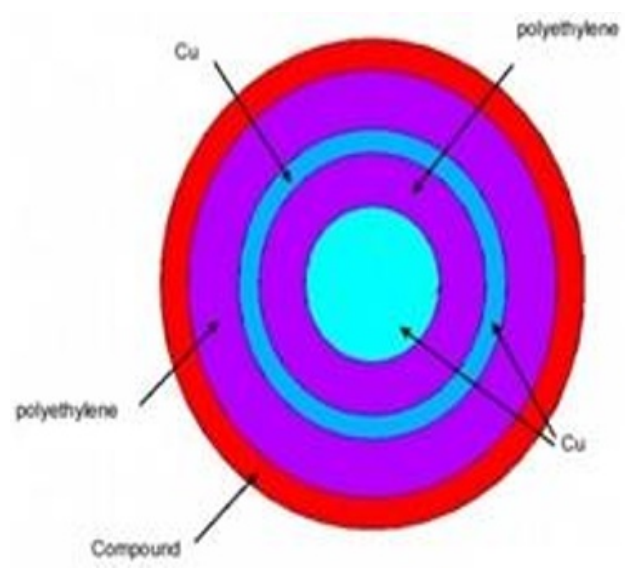

Table 1. Design param3eters of cables

\begin{tabular}{|c|c|c|c|}
\hline Parameter & Dimension & $\begin{array}{l}\text { SLIC } \\
\left(120 \mathrm{~mm}^{2}\right)\end{array}$ & $\begin{array}{l}\text { SLIC } \\
\left(400 \mathrm{~mm}^{2}\right)\end{array}$ \\
\hline Diameter of inner conductor & \multirow{5}{*}{$\mathrm{mm}$} & 14.5 & 23.5 \\
\hline Diameter of inner insulation & & 25.9 & 34.9 \\
\hline Diameter of external conductor & & 30.8 & 44.3 \\
\hline Diameter of external insulation & & 42.2 & 55.7 \\
\hline Outer sheath diameter & & 49.4 & 62.9 \\
\hline
\end{tabular}

The thickness of the inner and external layers of insulation is $5.7 \mathrm{~mm}$. On the conductors and on insulation, a screen is placed from the electrically conductive polyethylene composition LE 0540 of the company "Borealis". The external conductor is made in the form of 2 strands of copper wires with a diameter of $2.25 \mathrm{~mm}$ with a different direction of twisting for a cable with a cross-section of conductors of $300 \mathrm{~mm} 2(400 \mathrm{~mm} 2)$ and one coil - for cables with other sections.

To further minimize the inductance $[8,9]$, the cable assembly can consist of several parallel cables.

\subsection{Calculation of the main parameters and estimation of the maxi- mum cross-section of conductors}

The evaluation of the conductor cross-section in single-pulse mode should be performed in accordance with GOST 28895-91 (IEC 949-88) [10], which regulates thermally permissible shortcircuit currents. The maximum permissible amplitude $I$ of the current pulse in the mode of single pulses, $I=\varepsilon \cdot I_{A D}$, where $I_{A D}$ is the amplitude of the current pulse, calculated on the assumption of adiabatic heating, $\varepsilon$ is a coefficient taking into account the heat transfer to the neighbouring elements.

Let the heating be adiabatic $(\varepsilon=1)$, then 


$$
I_{A D}^{2} \cdot t=K^{2} S^{2} \ln \left(\frac{\Theta_{f}+\beta}{\Theta_{i}+\beta}\right), \quad \text { or } S=\sqrt{\frac{I_{A D}^{2} \cdot t}{K^{2} \ln \left(\frac{\Theta_{f}+\beta}{\Theta_{i}+\beta}\right)}}
$$

$t$ is the time (s); $K$ is a constant, depending on the material of the conductive element [10], (Ac) $1 / 2 / \mathrm{mm}^{2} ; S$ is the cross-sectional area of the conductive element, $(\mathrm{mm} 2) ; \Theta_{f}$ - final temperature $\left({ }^{\circ} \mathrm{C}\right) ; \Theta_{i}$ - initial temperature $\left({ }^{\circ} \mathrm{C}\right) ; \beta$ - value, inverse to the temperature coefficient of resistance of the conductive element at $0^{\circ} \mathrm{C}[10]$. For the nominal mode $\mathrm{I}_{\mathrm{AD}}=12 \mathrm{kA} ; \mathrm{t}=20 \mathrm{~s} ; \Theta_{f}=130^{\circ} \mathrm{C}$; $\Theta_{i}=20^{\circ} \mathrm{C} ; K=226^{(\mathrm{A} \cdot \mathrm{s})^{\frac{1}{2}}} / \mathrm{mm}^{2} \quad[10] ; \beta=234,5 K$ obtain $\mathrm{S}=396.2 \mathrm{~mm}^{2}$.

For non-adiabatic heating $\varepsilon=\sqrt{1+X \sqrt{\frac{t}{S}}+Y\left(\frac{t}{S}\right) X}=0.41\left(\frac{m m}{s^{0.5}}\right)$ $Y=0.12 \frac{\mathrm{mm}^{2}}{\mathrm{~s}}[10]$ we obtain $\mathrm{S}=379.6 \mathrm{~mm}^{2}$.

The assessment made it possible to choose for the areas of the cross-sections of the direct and return conductors of the SLIK operating in the nominal mode of single (rare) pulses equal to $400 \mathrm{~mm} 2$.

\subsection{Calculation of inductance}

The coaxial cable's inductance L consists of the internal inductance $L_{r}$ and $L_{R}$ of the conductors and the external (interconductor) inductance $\mathrm{L}_{\mathrm{IC}}[5]$ :

$$
L=L_{I C}+L_{r}+L_{R}+\frac{\mu_{0}}{8 \pi}=\frac{\mu}{2}\left[\frac{1}{\pi} \ln \frac{R}{r}+\frac{1}{\sqrt{2 \mu \gamma \omega}}\left(\frac{1}{r}+\frac{1}{R}\right)\right]+\frac{\mu_{0}}{8 \pi}
$$

With the diameter of the sealed multi-wire core $S=300 \mathrm{~mm} 2, d=0.3 \mathrm{~mm}$, the thickness of insulation, taking into account two polymer screens $\Delta=5.7+0.9+0.6=7.2 \mathrm{~mm}$, additional screen made of conductive cable paper thickness of $0.3 \mathrm{~mm}$, the diameter of an insulated radial core is $D=35.8 \mathrm{~mm}$ cable inductance is $\mathrm{L} 300=0.163 \mu \mathrm{G} \mathrm{m}$.

Formulas (2) are of an approximate nature. Calculating the inductance of the same cable using ELCUT [12] (FEM) yields $L=0.156 \mu \mathrm{G} \mathrm{m}$, excluding the stranding of the cores and $L=0.164 \mu \mathrm{G} / \mathrm{m}$ when taking into account stranding. As can be seen, the formulas (2) provide sufficient accuracy for estimating the inductance.

To study the dependence of the inductance of $L(f)$ on the frequency, a series of FEM calculations for different frequencies was carried out. The results are shown in Fig. 4. In general, the calculations showed that the value of the inductance of the pulsed cable with $S=300 \mathrm{~mm} 2$ does not exceed $0.2 \mu \mathrm{G} / \mathrm{m}$. 


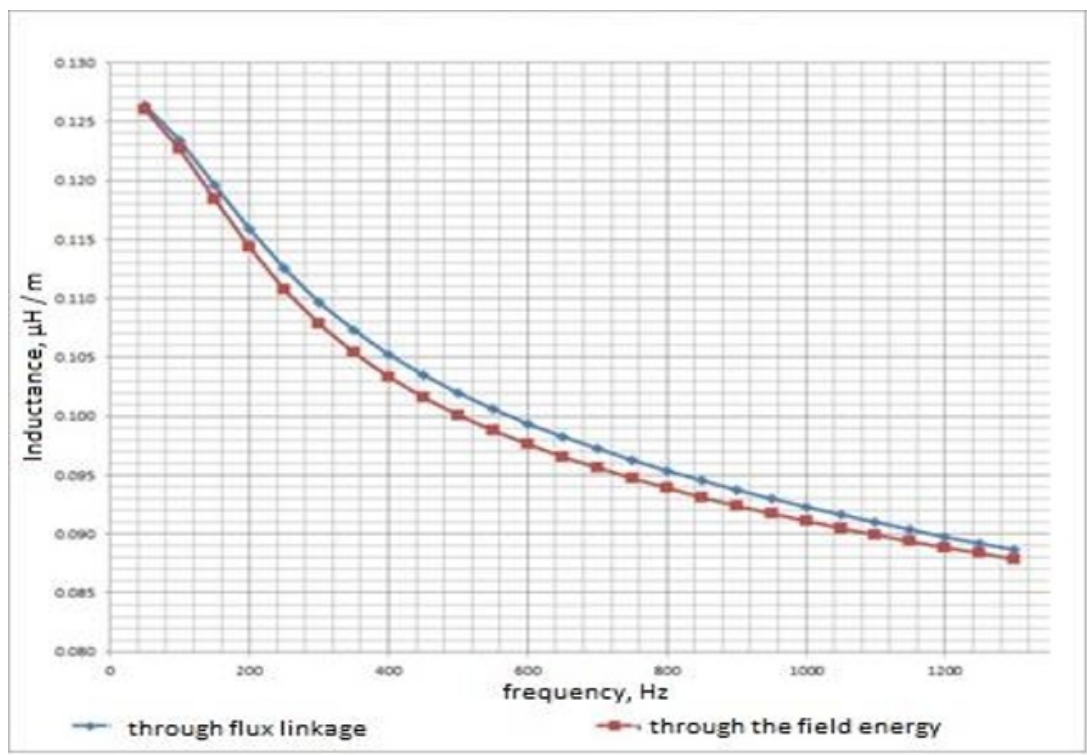

Fig. 4. Dependence of inductance on frequency.

\subsection{Calculation of the maximum conductor temperature in single pulse mode}

The thermal calculation of the cable $[5,7,13]$ consists of the calculating of the temperature variation of the conductors in time from the solution of the heat equation. The finite-element model $[14,15]$ of SLIC with the indicated triangulation [16] of the calculated FEM region is shown in Fig.5

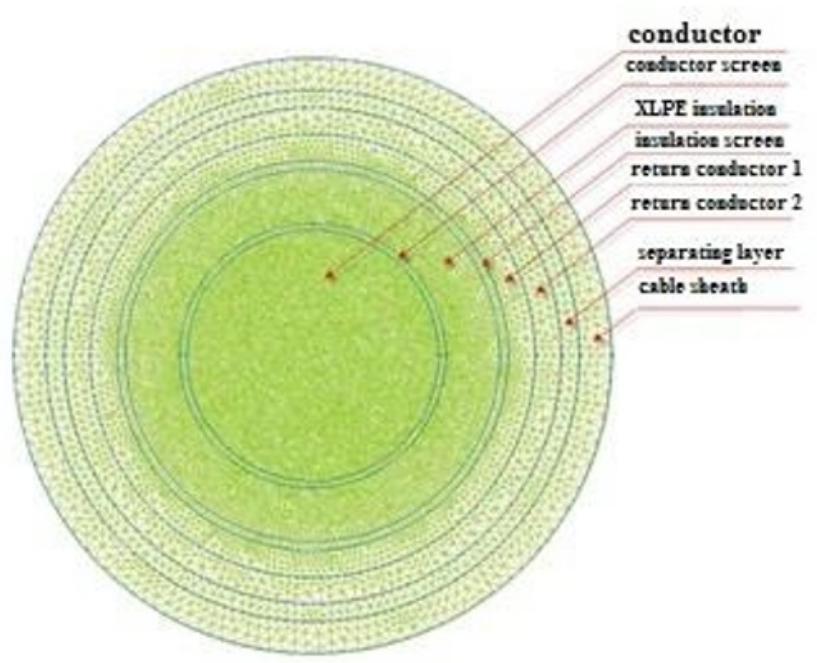

Fig. 5 Finite element model for thermal calculation. 
Table 3. Thermal properties of SLIC materials.

\begin{tabular}{|c|c|c|c|c|}
\hline Mark & Material & $\begin{array}{l}\text { Thermal conductivity } \\
\text { (W/(m deg) }\end{array}$ & $\begin{array}{l}\text { Heat capacity }(\mathrm{J} /(\mathrm{kg} \\
\mathrm{deg})\end{array}$ & $\begin{array}{l}\text { Density, } \\
(\mathrm{kg} / \mathrm{m} 3)\end{array}$ \\
\hline Conductor & multiwire copper & $\begin{array}{l}380 \cdot \text { filling fac- } \\
\text { tor }=0.75\end{array}$ & $\begin{array}{l}385 \cdot \text { filling fac- } \\
\text { tor }=0.75\end{array}$ & 8960 \\
\hline Conductor screen & $\begin{array}{l}\text { conductive polyeth- } \\
\text { ylene }\end{array}$ & 0.2 & 3000 & 1600 \\
\hline XLPE insulation & $\begin{array}{c}\text { Silane cross-linked } \\
\text { polyethylene }\end{array}$ & $\begin{array}{l}\text { at } 50 \mathrm{deg}-0.289 \\
\text { at } 100 \mathrm{deg}-0.248\end{array}$ & $\begin{array}{l}\text { at } 20 \text { degrees }-2300 \\
\text { at } 80 \text { degrees }-3760\end{array}$ & 948 \\
\hline Insulation screen & $\begin{array}{l}\text { conductive polyeth- } \\
\text { ylene }\end{array}$ & 0.2 & 3000 & 1600 \\
\hline return conductor 1 & $\begin{array}{c}48 \text { copper wires } d=2.25 \\
\text { mm }\end{array}$ & $380 \bullet$ filling factor $=0.7$ & $385 \cdot$ filling factor & 8960 \\
\hline return conductor 2 & $\begin{array}{c}50 \text { copper wires } d=2.25 \\
\mathrm{~mm}\end{array}$ & $\begin{array}{l}380 \bullet \text { filling fac- } \\
\text { tor }=0.65\end{array}$ & $385 \cdot$ filling factor & 8960 \\
\hline Separating layer & Compound & 0.2 & 3000 & 1600 \\
\hline Cable sheath & Compound & 0.2 & 3000 & 1600 \\
\hline
\end{tabular}

30

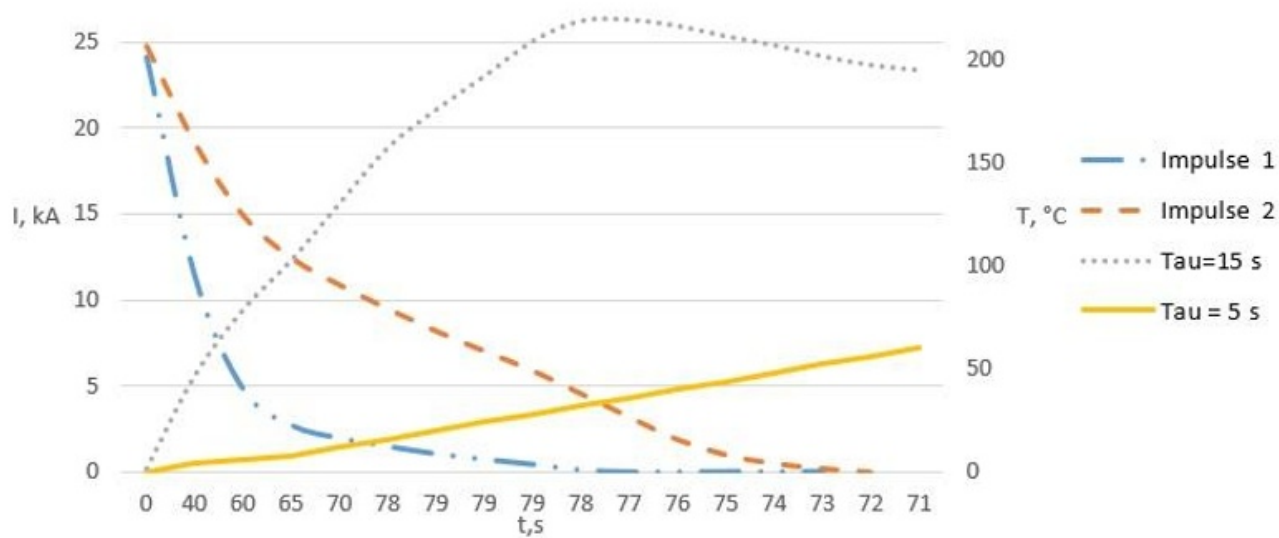

Fig. 6 Graph of the dependence of the surface temperature of the core on time (Tau=15 s, Tau $=5 \mathrm{~s}$ ) and the exponential current pulse in the conductor.

Analyzing the graph in Fig. 6, we would like to note that the presence or absence of a heat source in the return conductor has little effect on the value of the central core temperature, i.e. the heating of the radial conductor does not affect the character of heat transfer $[17,18]$ from the central core to the periphery of the cable.

Figure 7 shows the temperature distribution for $t=60 \mathrm{~s}$ over the cable cross-section when current pulse flows through the conductors with a time constant of $15 \mathrm{~s}$, which corresponds to the maximum central core temperature $T=220^{\circ} \mathrm{C}$. 


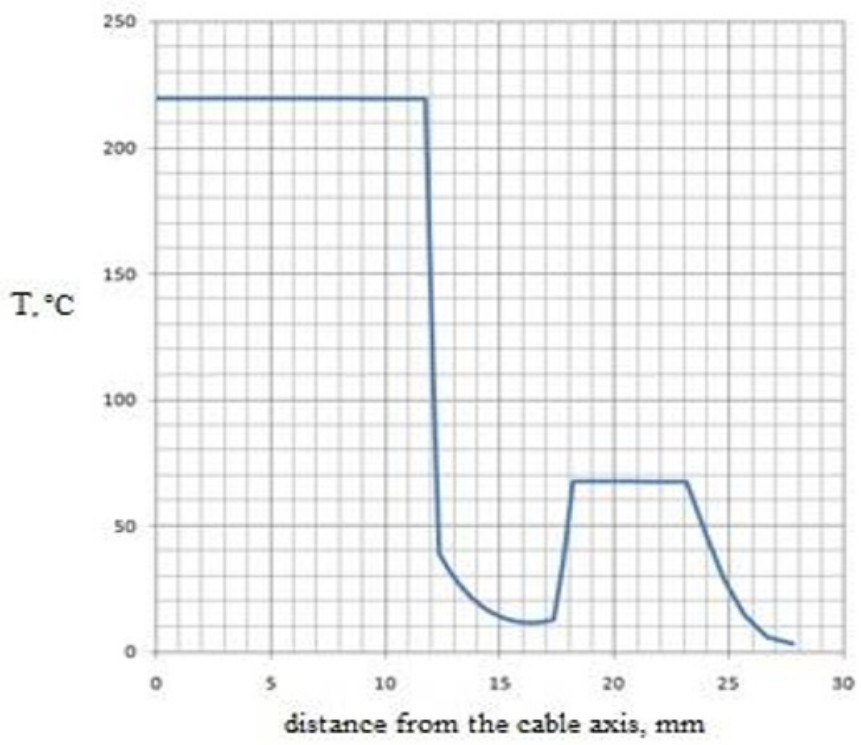

Fig.7 Temperature distribution over the cable cross-section.

The switching on of several SLICs in parallel will reduce the current load on each connected cable $[19,20]$. Calculations show that the temperature of the central core of the cable in the mode of a single current pulse with an amplitude of $25 \mathrm{kA}$ is $220^{\circ} \mathrm{C}$. In real conditions, a parallel connection of two or more cables should be used, which reduces the maximum core temperature to $55^{\circ} \mathrm{C}$.

\subsection{Conservation of insulation properties during the operation of the cable system (CS)}

A non-stationary thermal regime is considered in the insulation of cables $S=400 \mathrm{~mm}^{2}$ and $S=120$ $\mathrm{mm}^{2}$ with a single laying and at an ambient temperature of $+40^{\circ} \mathrm{C}$. The cable is laid partly in the premises, partly in the air, the intensity of solar radiation is $103 \mathrm{~W} / \mathrm{m} 2$, no wind.

The time constant $\tau$ of the electric transient is $20 \mathrm{~s}$. For a thermal process, the time constant will be approximately half the value, since the space density of heat release is proportional to the second degree of the current. Since the time of the electric transient is (3-4) $\tau$, then the calculated time will be taken equal to $40 \mathrm{~s}$.

The results of the calculation of the non-stationary thermal mode in $40 \mathrm{~s}$ after the beginning of the pulse are shown in Fig.8. The maximum temperature of the insulation layer located in direct contact with the core is $65.3^{\circ} \mathrm{C}$. The temperature distribution along the cable cross-section along its radius is shown in Fig. 9.

Table 4. Input data for calculation.

\begin{tabular}{|c|c|c|c|}
\hline Material & $\begin{array}{c}\text { Specific thermal conductiv- } \\
\text { ity } \\
\text { W/K*m }\end{array}$ & $\begin{array}{c}\text { Specific heat capacity } \\
(\mathrm{J} /(\mathrm{kg} * \mathrm{~K})\end{array}$ & $\begin{array}{c}\text { Specific weight } \\
\mathrm{kg} / \mathrm{m}^{3}\end{array}$ \\
\hline copper & 383 & 385 & 8990 \\
\hline XLPE, sheath, semicon. screen & Non-linear (Fig. 12) & Non-linear (Fig. 12) & 952 \\
\hline Polyethylene terephthalate & 0.19 & 1000 & 1.39 \\
\hline conductive paper Terkab & 0.15 & 1500 & 1.07 \\
\hline conductive tape Megatape & 0.1 & 1700 & 0.68 \\
\hline
\end{tabular}




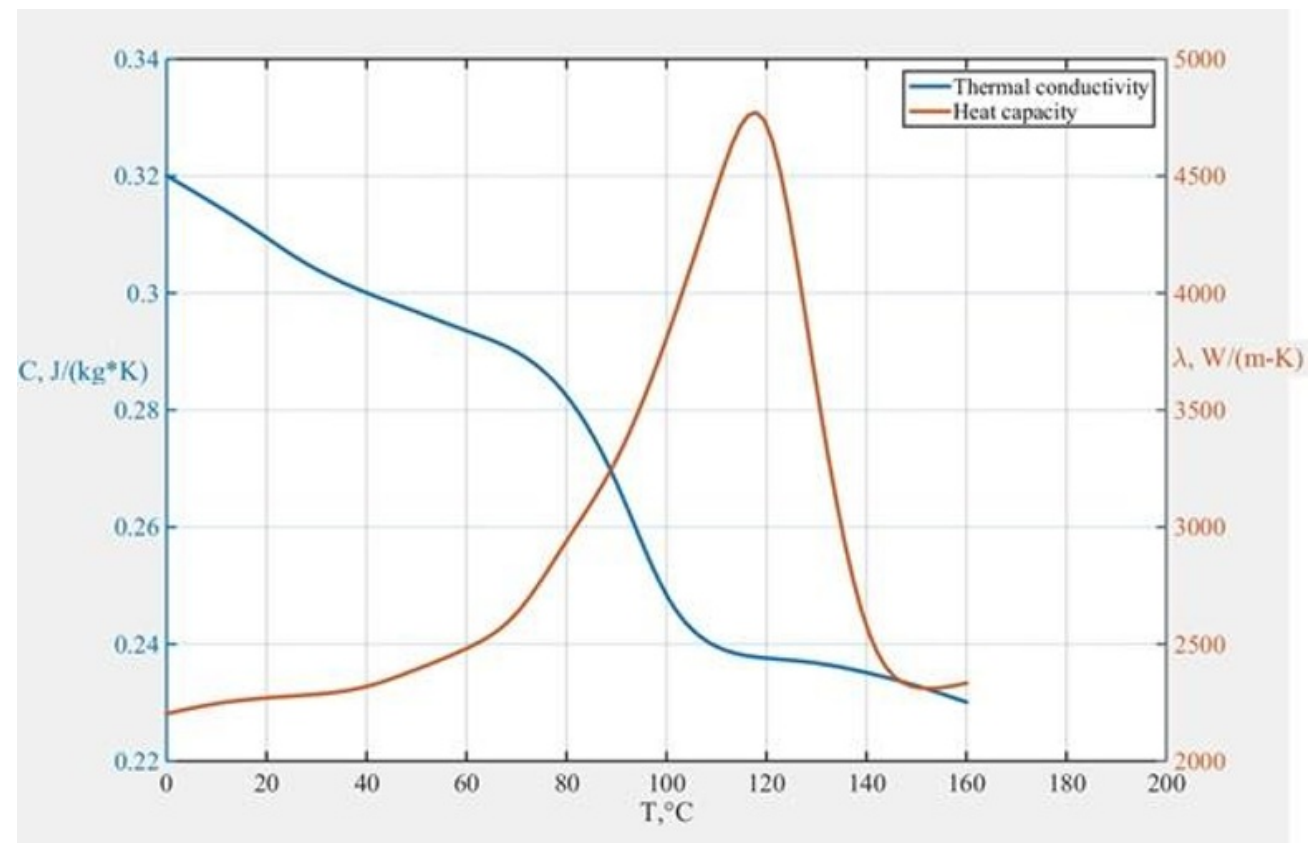

Fig. 8. Dependences of the thermal conductivity and heat capacity on temperature.
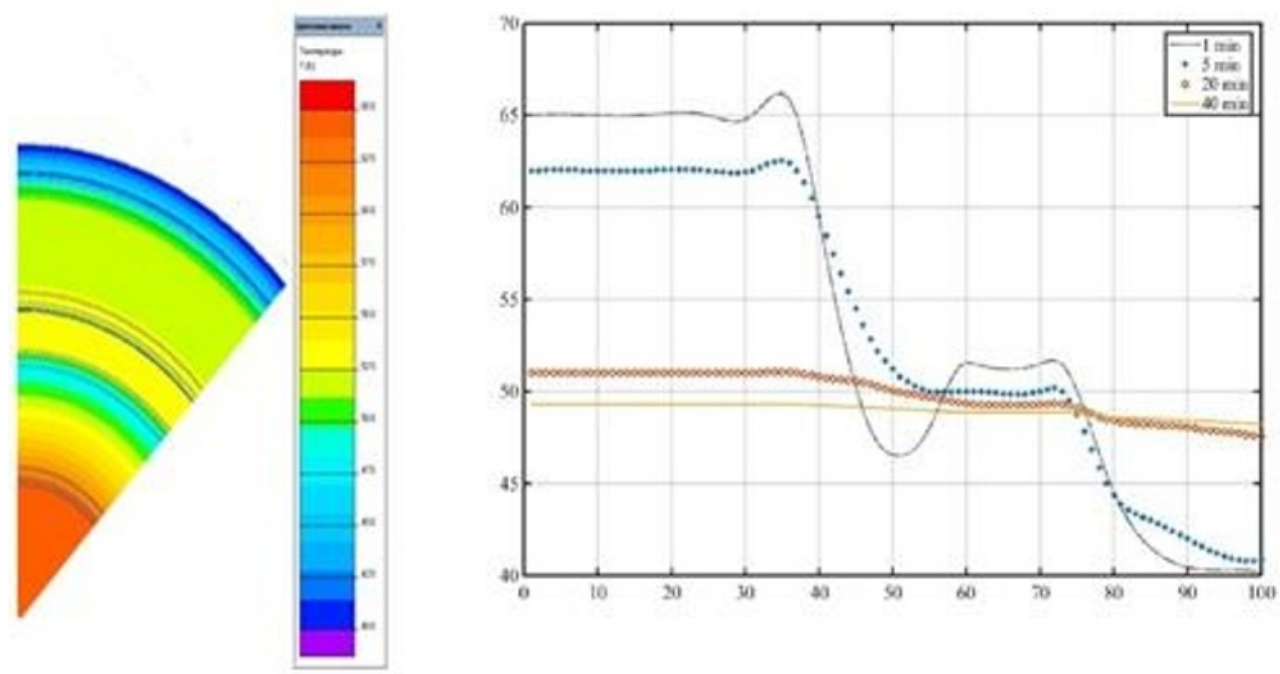

Fig.9. Colour chart of the distribution of the temperature field over the SLIK cross-section now of termination of the action of a single pulse, $t=40 \mathrm{~s}$. The temperature field diagram after 1, 5, 20, 40 minutes after the end of the pulse.

We show the dynamics of changes in the internal insulation temperature during cable cooling in the mode of rare (single) pulses in Fig. 9. 


\section{Discussion}

In the article, we considered the technique of calculation of designs of power low-inductive triaxle cables, which do not have direct analogues, for the ITER project.

The authors want to draw attention to the fact that the methods of calculation of inductance, thermal calculations given in the text, can be applied to the design of other types of cables and technical products. As an example, it is possible to give the option of use of SLIK in places of accession of loadings to capacitor stores of the electric power.

The use of FEM allows taking into account the maximum number of conditions under which the CS will operate. At the same time, it is interesting to compare the results obtained by numerical calculation, calculation based on the recommendations of the IEC with monitoring the operation of the CS in operation mode. The authors reserve the right to consider that the application of numerical methods gives a more accurate estimate than the calculation by IEC.

Now, all the cables considered in the article are made, and some have already been delivered to the customer. The necessary tests were also conducted and passed successfully.

\section{Conclusion}

We designed, manufactured and tested unique power low - inductive pulse cables for reliable high current connection of superconducting magnetic coils with energy absorbing resistors in the systems of operative and emergency removal of ITER energy; the authors also developed a calculation method for this type of CS.

\section{References}

1. R.Sh. Enikeev, A.G. Roshal, K.S. Sapozhnikov and others, February 13 - 17 (2017)

2. A. Roshal and others 86 (6-8), 1450-1453 (2011)

3. Demirchyan K.S., Boronin V.N., Kuznetsov I.F.. L.: Nauka, 280 p (1983)

4. Tokoprovod [web site]: - Access mode: http://shinoprovod.ru/shinoprovod/terminologiya/tokoprovody/ (date of circulation on 01/10/2018).

5. Greshnyakov G.V., Naryshkin E.V., Power electronics.-No.4. -P.42-46. (2009)

6. Greshnyakov G.V., Korovkin N.V., Kulikov A.V. Abstracts of the International Symposium on EMC and Electromagnetical Ecology. St. Petersburg. P.140-146 (2009)

7. G.V. Greshnyakov, M.V. Doronin, D.A. Seleznev. Fundamental and applied sciences today 2. Vol.1, p.118-120.

8. E.N. Bondarchuk, V.N Vasiliev., V.V. Titkov, N.A. Shatil, G.A. Shneerson Plasma installations and processes (English), No. 3, p.285-308 (1998)

9. GOST 2889-91 (IEC 949-88)

10. Specifications 3534-262-71378736-2012.

11. G.V. Greshnyakov, G.G. Kovalyov, N.V. Korovkin, S.D. Dubitsky. Use of computer modelling and numerical calculations to solve engineering problems. In the collection articles. St. Petersburg, Lubavitch, p. 5-74 (2015)

12. E.T. Larina. M. Energoatomizdat, 464 p (1996)

13. N.V. Korovkin, E.E. Selina. IEEE Int. Symp. on EMC Proceedings of the 1998 IEEE Int. Symp. on EMC. Part 1 (of 2). IEEE; editors: Anon. Denver, CO, USA. P. 946-951 (1998)

14. N. Korovkin, T. Minevich, Izvestiya Vysshikh Uchebnykh Zavedenii Rossii. Radioelectronics. Vol. 3. P. 54-61 (2006)

15. N.V. Korovkin, A.S. Adalev, M. Hayakawa. IEEE Trans. on Circuits and Systems I: Fundamental Theory and Applications. T. 55. No. 5. P. 1237-1247 (2008) 
16. Korovkin, N., Nitsch, J., Scheibe, H.-J. 2003 Source of the IEEE Int. Symp. on EMC. Vol. 2, № 1429120, P. 1148-1151 (2003)

17. Adalev, A.S., Korovkin, N.V., Hayakawa, M., Nitsch, J.B. 2006 Source of the IEEE Trans. on Microwave Theory and Techniques, Vol. 54, Issue 7, № 1650456, P. 31313139 (2016)

18. S. Dubitsky, G.Greshnyakov,N. Korovkin. 2016 IEEE Int. Energy Conf., ENERGYCON 2016, № 7514107 (2016)

19. Korovkin, N., Greshnyakov, G., Dubitsky, S, 2014 Electric Power Quality and Supply Reliability Conference, PQ 2014 - Proceedings 2014, № 6866837, P. 341-346 (2014)

20. N.V Korovkin, O.V. Frolov, E.A. Ivanova, , S.L. Shishiguin. IEEE Int. Symp. on EMC, № 6396752 (2012) 